\title{
Numerical and Experimental Study of Microvortex Generators
}

\author{
Andrew P. Heffron ${ }^{1}$, John J. Williams ${ }^{2}$, and Eldad Avital ${ }^{3}$ \\ Queen Mary, University of London, London, UK
}

A series of experimental and computational studies was conducted on vane-type microvortex generators (MVG) with the aim of better understanding the behaviour and to improve the design of such devices. The traditional rectangular and triangular vanes along with unique NACA0012 and E423 airfoils shaped vanes were studied with a height of $0.2 \delta$ while being embedded in a turbulent boundary layer of a flat plate. To assess the reliability of the numerical prediction of the drag forces acting on a MVG, a wind tunnel experiment was conducted. The experiment was conducted at a Reynolds number of 155, based on the friction velocity and the MVG height. A very good agreement was found between the experimental and numerical drag predictions for the MVGs with strong vortices. Fair agreement was found for the two MVGs with weak vortices.

From the four-specified vane-type MVGs, the best performing MVG configuration was sought by looking at the ratio of the vortex's circulation strength to the drag of the MVG vanes. It was found that triangular vanes had the best ratio and NACA0012 shaped vanes had the second best ratio. With altercation of the vane angle, vanes placed at angles of $18^{\circ}$ to $20^{\circ}$ had the best ratio. To supplement the performance study, the effect of the Reynolds number on the MVGs was also considered. A rectangular MVG vane was modelled at Reynolds numbers of 90 to 1150. A logarithmic relation was found between the Reynolds number of the MVG and the generated vortex's circulation and the drag of the MVG.

$\begin{array}{ll}C_{D} & \text { Drag coefficient based on freestream velocity } \\ d & \text { Outer diameter of the Pitot tube } \\ D & \text { Drag } \\ e & \text { Length of MVG vane }\end{array}$

\footnotetext{
${ }^{1}$ PhD Student, School of Engineering and Material Science, a.p.heffron@qmul.ac.uk, AIAA Student Member.

2 Emeritus Professor of Computational Fluid Dynamics, j.j.r.williams@qmul.ac.uk, Non-AIAA Member.

${ }^{3}$ Reader in Computational Fluids and Acoustics, e.avital@qmul.ac.uk, Senior AIAA Member (Corresponding Author).
} 


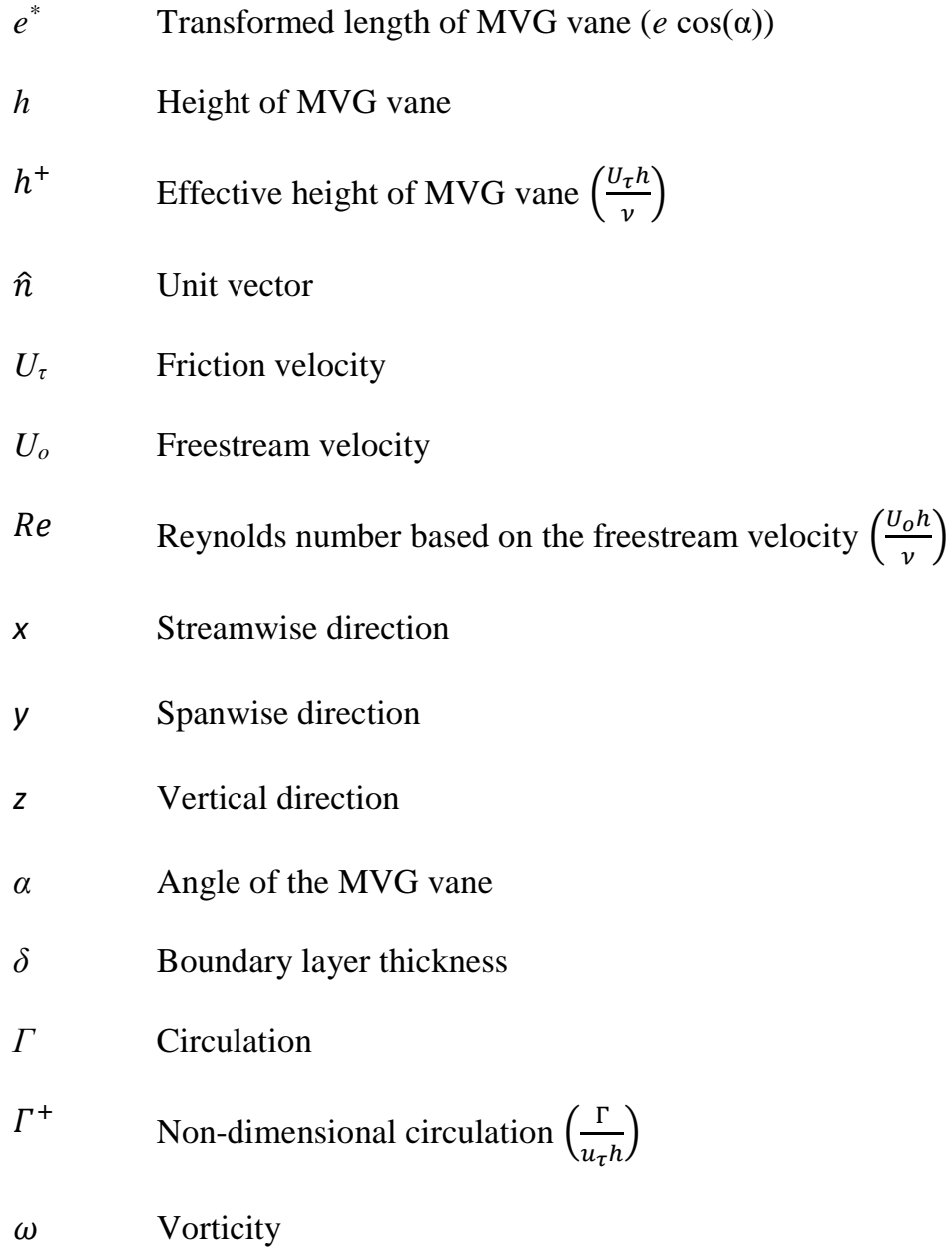

\section{I.Introduction}

Boundary layer separation is encountered in many applications that have extreme wall curvature and/or adverse pressure gradients. Flow separation can incur a large energy loss leading to many design strategies to inhibit the formation of flow separation. Vortex generators (VGs) offer a simple, inexpensive solution to this problem by generating a vortex that transfers momentum from the outer to the inner boundary layer that improves the health of the boundary layer. The usage of VGs are however accompanied by their own energy loss; it is therefore imperative to seek the best performing VG design. Ashill et al. [1] stated the effectiveness of a VG as the strength of the vortex and improvement in the shape factor of the boundary layer at the point of the needed flow control for a given unit of drag.

Numerous VGs designs and configurations have been developed to generate vortices in flows. Experimental work by Lin [2] found that VGs that generated streamwise vortices (i.e. vane-type VGs) were the most effective in delaying flow separation on a high-lift airfoil. Further work by Lin et al. [2, 3] found that a 
vane-type VG could be reduced down to $20 \%$ of the boundary layer thickness which reduces the drag of a VG while retaining their effectiveness in supressing separation. Further reductions in height degraded the effectiveness of VGs in controlling separation. Lin [2] called these sub-boundary layer VGs microvortex generators (MVGs). Another optimization study was conducted by Godard and Stanislas [4] with a turbulent flow on a bump using skin friction to qualitatively measure the performance of MVGs. Among their findings, they found vanes angled at $18^{\circ}$ and triangular vanes were the most efficient. The angle of $18^{\circ}$ was also found to be the optimum angle by Pauley and Eaton [5]. Several authors have also experimented with alternative vane shapes in the form of trapezoids and airfoils [6-8].

Ashill et al. $[9,10]$ conducted experimental characterization studies that correlated multiple MVG configurations over a range of Reynolds numbers. They were able to demonstrate a correlation between the downstream vortex strength to device's Reynolds number by the use of the device's effective height. Ashill et al. [10] also measured the drag of MVGs by the momentum deficit in the downstream boundary layer with a zero and an adverse pressure gradient. Their numerical predictions of the drag of the MVGs matched reasonably well to their drag measurements. In contrast, Lin et al. $[2,11]$ used a force balance to measure the drag of MVGs.

Computationally, two approaches have been taken to model vortex generators in the literature. The most obvious approach is directly modelling the MVG and the generated vortex. Work by Ashill et al. $[9,10]$, Allan et al. [12], and Wik et al. [13] found RANS modelling gave accurate predictions of MVGs and their vortices, even when using a very coarse mesh. Furthermore, Ashill et al. [10] found RANS modelling to give a reasonable prediction of drag MVG vanes when compared to experimental values. The second approach is to neglect the modelling of MVG and use a lifting-force to artificially generate a vortex. The lifting-force, or Bender-Anderson-Yagle (Bay), model was proposed by Bender et al. [14]; an improved version has been proposed by Jirásek [15] called the jBAY model. The latter approach allows for a vortex to be studied in application without the computational cost of modelling a MVG directly while the former approach allows for a more realistic appraisal of a MVG has on the flow. Florentie et al. [16] found the BAY and jBAY models to be very dependent on the mesh resolution and resolving the VG vane lead to better results when compared to experimental results.

The objective of this study is to determine best performing shape and angle of a vane-type MVG. Vane-type MVG generating streamwise vortices are commonly used to control flow on airfoils, diffusers, etc. In 
this study, the optimal performance is defined by the downstream circulation of a generated vortex versus the drag of the vane. Circulation is the measure of the rotation of a fluid structure and can be equated to the transfer of momentum in the case of a vortex embedded in a boundary layer. Although the amount of circulation needed to reduce or eliminate flow separation can be case dependent, a MVG can be designed around the required circulation. Although multiple vanes are typically used as a system to control flow separation, an isolated vane in a low-speed, zero-pressure gradient flow is studied to limit the number of parameters. To validate the computational results presented in this study, an experimental study was conducted in conjunction with the numerical study to experimentally determine the drag of MVG vanes and their effects on the boundary layer flow structure.

\section{II.Method of Analysis}

A MVG and the generated vortex can be defined by several parameters. The MVG can be defined by its drag and initial circulation strength while the evolution of the downstream vortex can be defined by the circulation strength, peak vorticity, radius, skin friction on the wall, and position of the vortex core at a measured point. Different techniques and methods can be used to evaluate these parameters.

A MVG system generators drag directly from the pressure and viscous forces acting on the device and indirectly from the increase of viscous forces (skin friction) on the downstream surface caused by the vortex. The summation of the direct and indirect drag yields the total drag that the MVG system that contributes to the drag of the applied body. With numerical results, the direct and indirect drag can be calculated individually by the summation of the pressure and viscous forces acting on the MVG and the downstream surface. Experimentally, the total drag of the system can only be determined and is determined by measuring the momentum deficit at a measurement plane.

The parameters of the vortex were determined at incremental downstream planes, the planes were normal to the wall surface. The vortex was identified with the Lambda-2 method [17]. The vortex core itself was identified by the eigen-analysis method proposed by Haimes and Kenwright [18]. However, it is noted that the position of the vortex core identified by the eigen-analysis method differed very little from the position identified from the peak vorticity.

The radius of the vortex was approximated by obtaining the mean distance of the isocline of $50 \%$ of the peak vorticity to the vortex core. The circulation was evaluated by taking the surface integral of the vorticity vector dotted with a unit vector. For the enclosed work, the unit vector corresponded with the direction of the freestream velocity yielding the vortex's circulation in the streamwise direction. 


$$
\Gamma=\iint \boldsymbol{\omega} \cdot \widehat{\boldsymbol{n}} d S .
$$

In the calculation of the circulation, the vorticity was clipped to $1 \%$ of the peak vorticity at $\mathrm{x} / \mathrm{h}=1$ to eliminate any numerical noise that was present. Clipping the vorticity for RANS had little impact on the calculation of the circulation. Immediately downstream of the vane, the calculated circulation with clipping and non-clipping were equal, but much further downstream, the use of clipping tended to reduce the magnitude of the circulation. The circulation was non-dimensionalized with the height of the MVG and local friction velocity at the MVG location.

\section{III.Experimental Setup}

The QMUL wind tunnel No. 4 is a closed-circuit wind tunnel that can be operated up to $35 \mathrm{~m} / \mathrm{s}$. The working section has a length of $2 \mathrm{~m}$, a width of $0.52 \mathrm{~m}$ wide, and a normal height of $0.38 \mathrm{~m}$, the walls are slightly divergent to compensate for boundary layer growth. The test section is split in the centre by a precisely machined flat plate to generate the desire boundary layer, reducing the width of the test section to $0.25 \mathrm{~m}$. The boundary layer was tripped $0.065 \mathrm{~m}$ from leading edge of the flat plate with a metal rod. The centre of the flat plate has 18 static pressure taps distributed in the streamwise direction and the stagnation pressure was measured with a pitot tube mounted on a traverse. The traverse allows for the Pitot tube to be moved three dimensionally with increments of $5 \mu \mathrm{m}$. The pressure measurements were measured with a DSA3217 scanning valve that takes 32 scans per pressure measurement. The freestream turbulence intensity in the test section was measured to be $0.1 \%$.

The tested MVG vanes were mounted $0.515 \mathrm{~m}$ from the leading edge of the plate in the centre of the test section to ensure a steady boundary layer. The measured freestream velocity was $15.79 \pm 0.33 \mathrm{~m} / \mathrm{s}$. The boundary layer thickness and the momentum thickness were measured to be $16 \mathrm{~mm}$ and $1.37 \mathrm{~mm}$ at this point, respectively. The MVG height was scaled to $0.2 \delta$ and was placed $23^{\circ}$ relative to the flow direction. Five different MVG shapes were tested: two rectangle vanes, a triangular vane, a vane based on the NACA0012 airfoil, and a vane based on the E423 airfoil.

A survey of the flow behind the MVG vane was conducted 53h behind the vane. The survey was composed of 24 boundary layer profiles that were taken in the spanwise direction along a $104 \mathrm{~mm}$ space. The boundary layer profiles were composed of 45 measurements in the normal direction. The first measurement was taken $0.15 \mathrm{~mm}$ away from the wall and measurements were taken until the pitot tube was $22.15 \mathrm{~mm}$ above the wall. Each survey took 12 to 14 hours to complete where any drift in the freestream velocity was found to be 
negligible. To reduce the uncertainty of the final drag measurement, each MVG was surveyed multiple times, with the number of surveys conducted for each vane is shown in Table 1. Each survey was subtracted from an averaged baseline survey with no MVG. The difference was then numerically integrated to obtain the total drag generated by each vane. The calculation procedure to obtain the drag coefficient is shown in Appendix A.

\section{IV.Experimental Results}

Five MVG vanes were experimentally tested, which are shown in Table 1. The averaged Reynolds number for the experimental tests was 3326, based on the freestream velocity at the MVG position and the height of the MVG. The friction velocity was calculated via two methods, a curve fitting method suggested by Kendall et al. [19] and a correlation method developed by Patel [20]. The curve fitting method suggested by Kendall et al. [19] gave a friction velocity of 0.744 and $\mathrm{h}^{+}$of 155.03 . Patel [20] correlation method is an extension of Preston's method [21] which uses the dynamic pressure at the wall to obtain the friction velocity through a correlation. The correlation method proposed by Patel [20] gave a friction velocity of $0.767 \mathrm{and} \mathrm{h}^{+}$of 159.80. The uncertainty of the measured experimental values and the uncertainty of the calculated drag coefficient was determined by the procedures published in "Quality Assessment for Wind Tunnel Testing" [22].

To compare the experimental results in Table 1, a corresponding set of numerical models with a similar Reynolds number to that of the experiment was conducted. The MVG height was scaled $20 \%$ of the boundary layer thickness, and the freestream and boundary layer thickness was adjusted to achieve the experimental Reynolds number. To account for the drag caused by the viscous interaction of the vortex with the wall and to give a good comparison, the numerical results were evaluated at $53 \mathrm{~h}$ behind the vane. The drag coefficient is based on the freestream velocity and the height of the MVG.

Table 1: Experimentally and computationally obtained drag values

\begin{tabular}{|l|c|c|c|c|c|}
\hline \multicolumn{5}{|c|}{ Experimental } & Numerical \\
\hline MVG Shape & $\mathrm{e} / \mathrm{h}$ & No. of Trials & $\operatorname{Avg~} \mathrm{C}_{\mathrm{D}}$ & $\pm(\%)$ & $\mathrm{C}_{\mathrm{D}}$ \\
\hline Rectangle & 7 & 6 & 1.0020 & 3.52 & 1.0512 \\
\hline Rectangle & 3 & 6 & 0.5707 & 16.78 & 0.6153 \\
\hline NACA0012 & 3 & 5 & 0.4907 & 19.74 & 0.4332 \\
\hline Triangle & 3 & 7 & 0.2626 & 31.51 & 0.2316 \\
\hline E423 & 3 & 5 & 0.7704 & 3.96 & 0.8076 \\
\hline
\end{tabular}

The drag coefficient compares well between numerical and experimental results. The uncertainty error for the drag measurements for the rectangle $\mathrm{e} / \mathrm{h}=7$ and $\mathrm{E} 423$ vanes was found to be small but was significant for the other vanes, particularly for the triangle vane. It is postulated that the uncertainty is inversely proportional to 
the magnitude of the drag. As shown and discussed later, the drag is also proportional to the circulation, and the rectangle $\mathrm{e} / \mathrm{h}=7$ and $\mathrm{E} 423$ vanes were observed to generate the strongest circulation.

\section{V.Numerical Setup}

The parametric study solved the steady-state RANS approach using the commercial software ANSYS® Fluent 14.5/15.0. The convective terms were solved with a 2nd-order upwind discretization in conjunction with the SIMPLEC pressure solver. The turbulent viscosity was modelled with the k- $\omega$ SST turbulence model.

The computational domain consisted of a vane-type MVG mounted on a flat-plate that extended 125 $\mathrm{mm}$ upstream and $800 \mathrm{~mm}$ downstream of the leading edge of the MVG. A velocity inlet was imposed upstream and a pressure outlet boundary condition was imposed downstream of the MVG. The pressure gradient across the domain was zero. A turbulent boundary layer profile was read into the inlet to generate a boundary layer thickness of $35 \mathrm{~mm}$ at the MVG's location. The turbulent boundary layer was generated by a prior simulation on a flat plate with an inlet turbulence intensity of $1 \%$ and an imposed velocity to obtain the desired boundary layer thickness. For the validation and optimization study (Subsections VI.A and VI.B), a freestream velocity of 34 $\mathrm{m} / \mathrm{s}$ and a boundary layer thickness of $35 \mathrm{~mm}$ was used. The Reynolds number based on the friction velocity and MVG height, $\mathrm{h}^{+}$, was 607 , while the Reynolds number based on the freestream velocity and MVG height was 16,533. To study the effect that the Reynolds number has on the MVG and vortex parameters (Subsection VI.C), the boundary layer thickness was held constant at $35 \mathrm{~mm}$ and the freestream velocity was varied to produce a range of Reynolds numbers $\left(90<h^{+}<1150\right)$. Periodic boundary conditions were imposed $200 \mathrm{~mm}$ apart in the spanwise direction. No-slip boundary conditions were enforced along the solid surface of the MVG and the wall. The domain extended $200 \mathrm{~mm}$ vertically from the wall.

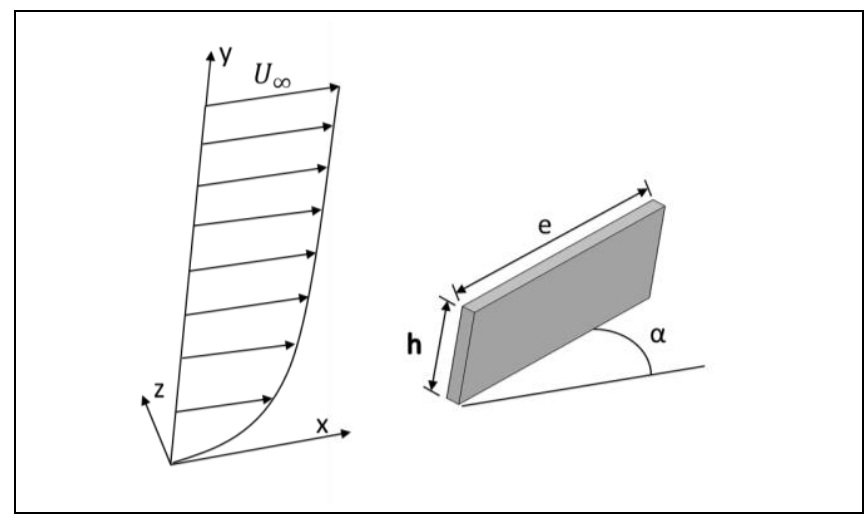

Figure 1: MVG geometry

The generated meshes had a maximum $\mathrm{y}^{+}$of 1 on the wall and 5 on the vane surface. The unstructured, hexahedral mesh was generated with ANSYS® ICEM. The mesh topology for Mesh B is illustrated in Fig. 2. 
To limit the number of parameters, only a single vane was modelled. The MVG vane modelled had a height (h) of $0.2 \delta$ and a length that varied between $\mathrm{e} / \mathrm{h}=3$ and $\mathrm{e} / \mathrm{h}=7$. The angle was varied from $10^{\circ}$ to $29^{\circ}$. A diagram of the MVG vane is shown in Fig. 1.

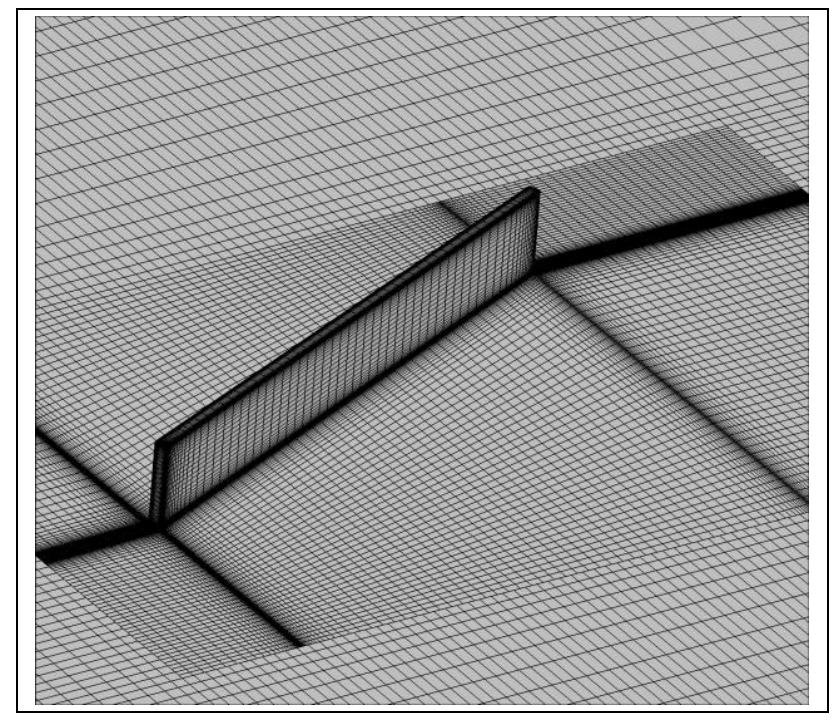

Figure 2: Mesh topology (Mesh B)

\section{VI.Numerical Results}

\section{A. Validation}

A numerical grid convergence study was conducted in an attempt to quantify the influence that mesh resolution had on the different parameters of a MVG and its vortex. The study used the experimental results of Yao et al. [23] to check the sensitivity of the mesh resolution. Following Yao et al. [23] work, the circulation, trajectory and radius of the vortex were calculated as shown in the Fig. 3. Three different mesh densities were generated as shown in Table 2 to demostrate the dependence of the MVG and generated vortex on mesh resolution. To generate the three mesh densities, the mesh was refined in the spawnwise and streamwise directions along with the expansion ratio while maintaining the initial cell height at the wall as constant.

Table 2: Mesh densities and sensitivity of the drag

\begin{tabular}{|l|c|c|c|c|}
\hline & Number of & \multicolumn{3}{|c|}{$\mathrm{C}_{\mathrm{D}}$} \\
\cline { 3 - 5 } & Cells & $10^{\circ}$ & $16^{\circ}$ & $23^{\circ}$ \\
\hline Mesh A & $11.6 \mathrm{M}$ & 0.2301 & 0.4786 & 0.9802 \\
\hline Mesh B & $6.1 \mathrm{M}$ & 0.2298 & 0.4774 & 0.9762 \\
\hline Mesh C & $3.8 \mathrm{M}$ & 0.2340 & 0.4811 & 0.9734 \\
\hline
\end{tabular}




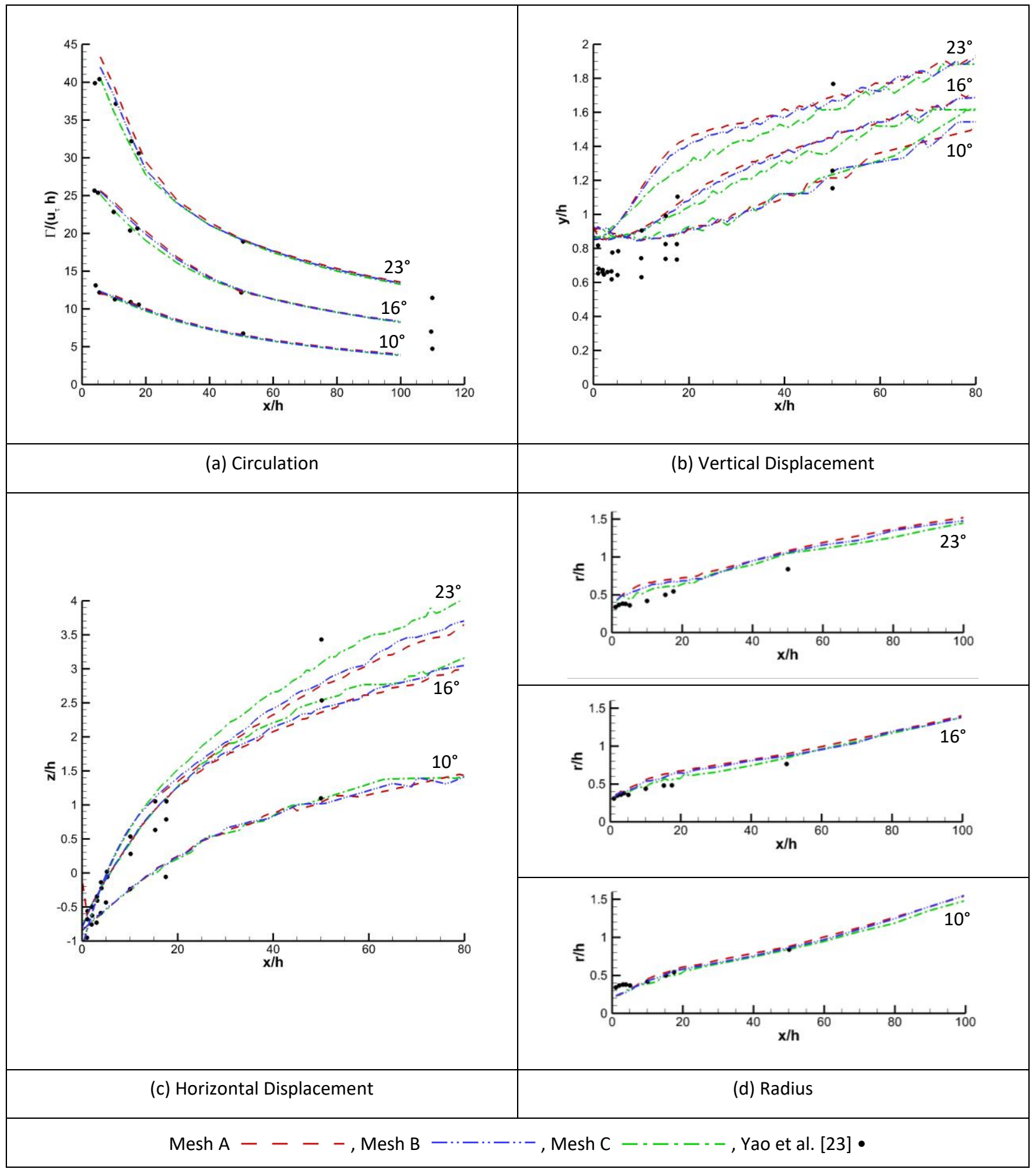

Figure 3: Vortex parameters dependencies on mesh resolution

From Table 2, the drag from the MVG vane varied little between the three meshes; the largest deviation between Mesh A and C was $1.7 \%$ and between Mesh A and B was $0.2 \%$. Similarly, the initial circulation showed a slight sensitivity to the mesh resolution, and it matched well to the experimental data, as shown in Fig. 3-a. The biggest sensitivity in the mesh resolution was observed for the vane placed at $23^{\circ}$ after the vortex was initially formed, vanes placed at smaller angles showed less of a variation. Further downstream, the circulation was observed to be less sensitive to the mesh resolution for all three vanes. The trajectory of the 
vortex proved to be more sensitive to the mesh resolution and there was a slight discrepancy between the computationally predicted path of the vortices and what Yao et al. [23] experimentally observed as shown in Fig. 3-b and 3-c. The mild discrepancies between the computational and published results were most clearly seen in the vertical displacement of the vortex. The vortices were seen to depart from the vane further from the wall than published results as shown for all three vanes. However, the horizontal displacement matches quite well with the experimental results. Lastly, shown in Fig. 3-d is the sensitivity of the radius of the vortices to mesh resolution and comparison to Yao et al. [23] results. There is a slight variation in the sensitivity to mesh resolution for the radius of the vortices. The predicted radius also matches well with the published data.

\section{B. MVG Efficiency}

From the results of previous subsection, a set of MVG configurations were studied to determine an optimal configuration. As with the numerical results of Wik and Shaw [13], the parameters of the MVG and the vortex were found to be quite insensitive to the mesh resolution. However, to ensure the best results a mesh resolution similar to Mesh A from the previous subsection was used to model the MVG configurations.

This study of MVGs makes the assumption that a MVG system can be broken down into the formation of the vortex (the MVG), and the evolution of the vortex downstream of the MVG. This is similar in concept to the jBAY model $[14,15]$. From this assumption, the evolution of the vortex can be defined as a function of the initial state of the vortex after it forms. This also allows for the formation of the vortex on the MVG to be studied and optimized around a desired initial vortex state. Ashill [1] dictated that the effectiveness of a MVG is the strength of the vortex and the improvement in the shape factor of the boundary layer per unit of drag. The vortex circulation, which is the measure of the momentum transfer in the boundary layer, directly controls any improvement in the shape factor. In the following work, vortex circulation is used instead of a change in the boundary layer shape factor to evaluate the effectiveness of a MVG. Based on prior published research [11, 24] that found the vortex had the strongest interaction with the wall at of $\mathrm{x} / \mathrm{h}=10$, the vortex circulation was evaluated at this downstream point. Therefore, the efficiency of a MVG in this paper is equal to the ratio of the vortex circulation at $\mathrm{x} / \mathrm{h}=10$ to the drag of the $\mathrm{MVG}$ vane.

Before looking at the dynamics of vortex formation on the MVG, the downstream behaviour of the vortex will be studied to see how well this assumption holds. Varying the angle of MVG vane between $10^{\circ}$ to $29^{\circ}$ and using vane lengths $(\mathrm{e} / \mathrm{h})$ of 3,5 , and 7 , the vortex behaviour downstream of the MVG was recorded. Shown in Fig. 4 is the circulation and in Fig. 5 the y-position of the vortex downstream of the MVG with 
respect to the initial circulation. The vortex circulation at a given point downstream of the MVG follows a parabolic function with the initial circulation and as expected, the stronger circulation vortices decay faster. However, the circulation generated by the $\mathrm{e} / \mathrm{h}=3$ and $\mathrm{e} / \mathrm{h}=5,7$ differs slightly. The $\mathrm{y}$-trajectory of the vortex follows a similar pattern as the vortices propagate downstream except that the trend is less pronounced.

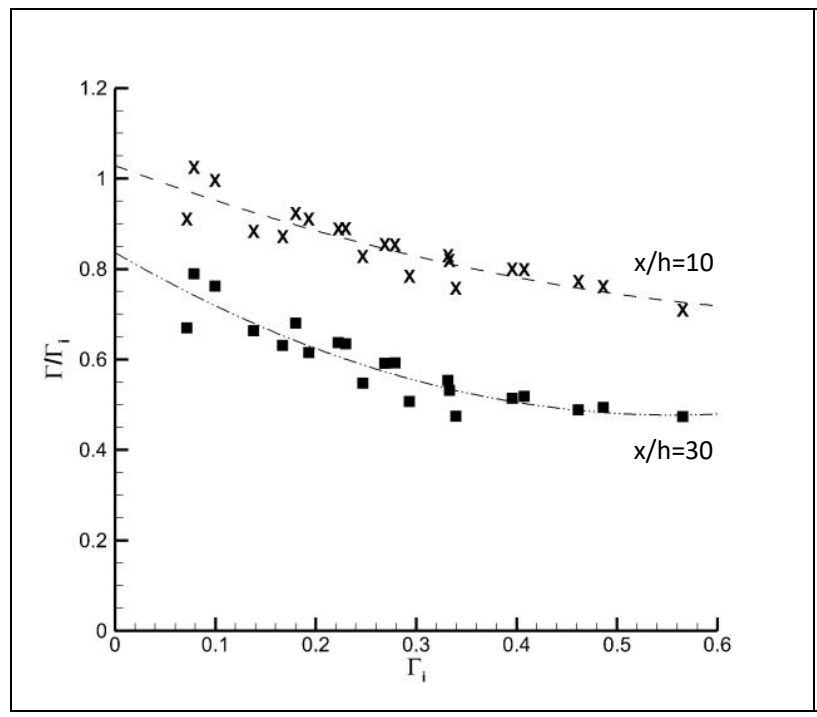

Figure 4: Dependency of downstream circulation on initial circulation

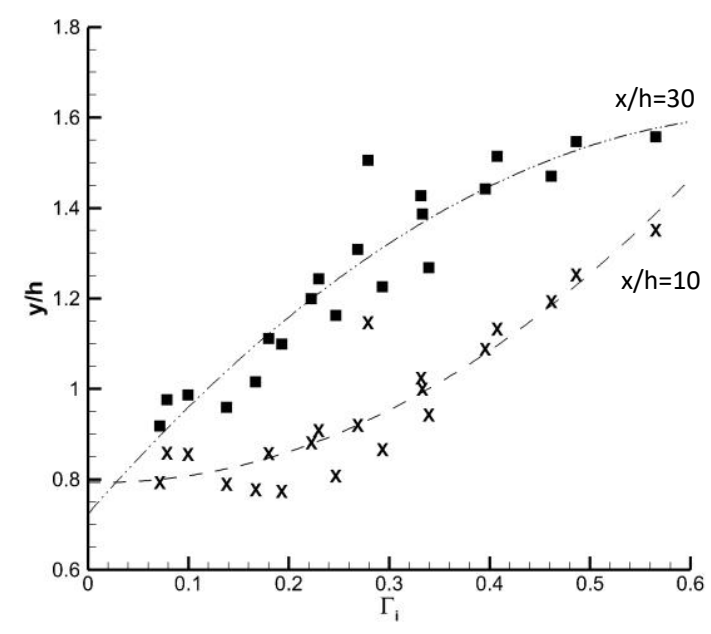

Figure 5: Dependency of downstream position on initial circulation

Establishing that the evolution of a vortex downstream can be described just by its initial state, the formation of the vortex on a MVG can be studied as a separate unit and improved around the initial properties of the generated vortex. Using the same models used previously, the relationship of the circulation at $\mathrm{x} / \mathrm{h}=10 \mathrm{can}$ be compared to the change of angle, as shown in Fig. 6. In addition to the standard rectangle vanes, three other shapes were tested, a triangle vane and vanes in the form of the NACA 0012 and E423 airfoils. Triangle vanes have been used extensively in literature. Airfoil shaped vanes were tested with the idea that MVG vanes operate in a similar manner to wings and using a more aerodynamic shape may increase circulation and decrease drag. The non-rectangle vanes were tested with a length of $3 \mathrm{~h}$.

From Fig. 6, the initial circulation of the generated vortex increases with an increase of angle. At low angles of attack, initial circulation is a linear function of the angle. Increasing the vane angle above $20^{\circ}$ shows a diminishing increase of circulation. The precise angle at which circulation began to experience a diminishing increase of circulation varied with the vane shape. Comparing the vanes, the triangle vanes were observed to produce the weakest circulation. The airfoil shaped vanes gave mixed results, the E423 produced much stronger vortices while the NACA 0012 produced weaker vortices when compared to rectangle vanes. Increasing the length of the vane increased the initial circulation of the vortex. 


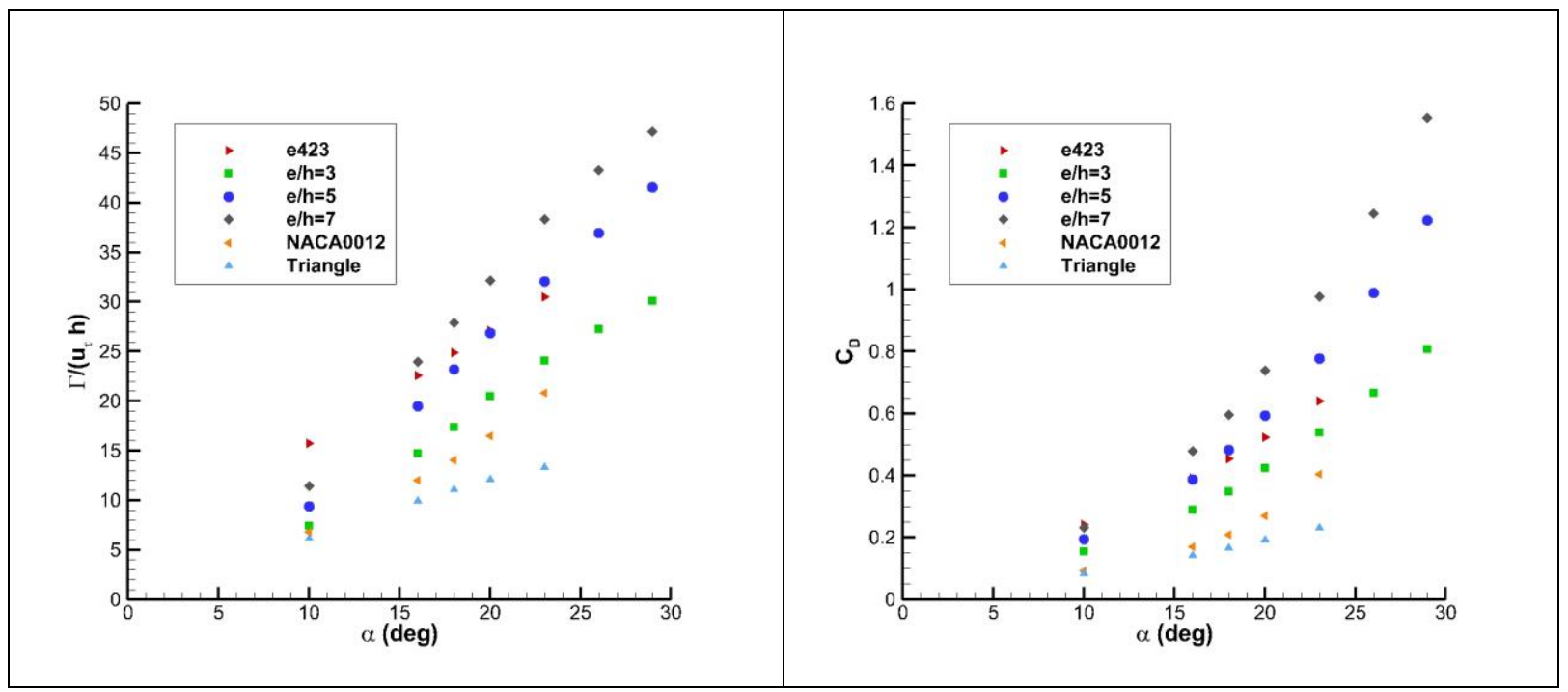

Figure 6: Initial circulation dependence on vane angle

Figure 7: Drag coefficienct dependence on vane angle

The benefits of MVGs are not without a loss of energy (drag) in the flow and the implementation of MVGs has to be judged on their improvement to the flow versus the drag they themselves add to the overall system. Shown in Fig. 7 is the drag coefficient of the vane per angle. The drag of vortex on the wall downstream was neglected and only the drag of the vane itself was considered. Similar to the vortex circulation generated by the vane, the drag increases with vane angle. However, unlike the vortex circulation, the drag incrementally increases with an increase of angle.

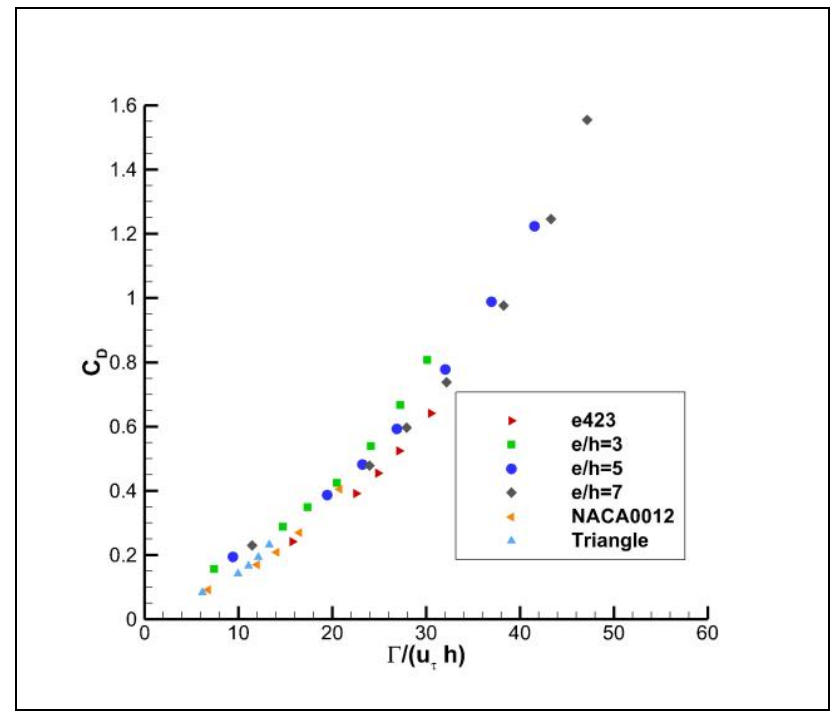

Figure 8: Drag coefficienct vs initial circulation

A plot can be created from plotting the circulation of the generated vortex versus the drag of the vane as shown in Fig. 8. From the plotted data, the drag of the vane is observed to increase as an exponential function of the initial circulation. This exponential relation is observed for each vane shape and as a global set. Two 
distinct groups can be observed in the plotted data. Rectangle vanes had a slightly higher drag to circulation ratio due to a flow separation problem that will be discussed later while the airfoil shaped and triangle vanes had a better circulation to drag ratio. Furthermore, increasing the vane angle decreases its efficiency by a combination of a diminishing return of a circulation increase and an increase of drag. The efficiency of a given vane decreases significantly after $18^{\circ} / 20^{\circ}$ and it becomes practical to adopt a new vane shape that generates a stronger vortex.

To provide better insight into the results that were shown previously, the streamwise vorticity and velocity contours are shown in Figs. 9 and 10. In Figs. 9 and 10, the flow fields at 5 streamwise points along the vane were studied for four different MVG shapes. The vanes had an angle of $18^{\circ}$ relative to the flow direction. For the rectangle vanes and triangle vanes, initial vortex formation occurs on the forward section of the vane. By $\mathrm{x} / \mathrm{e}^{*}=0.2504$, the vortex has begun to roll up, and by $\mathrm{x} / \mathrm{e}^{*}=0.5007$ the vortex has begun to detach from the vane surface. Similarly, the vortex formation occurs near the leading edge of the triangle vane but the vortex continues to grow up to the trailing edge of the vane. The vortex at the trailing edge of the triangle vane is closer to the wall than the vortex of the other vanes. In contrast, the vortex formation for the NACA0012 and E423 shaped vanes are delayed until on the second half of the vane.

Further insight can be obtained by studying the velocity contours in Fig. 10. Rectangle vanes have a noticeable separation bubble on the leading edge of the vane. The separated flow is not suppressed until the vortex has gained sufficient strength at approximately $\mathrm{x} / \mathrm{e}^{*}=0.5007$. The separated flow increases the drag of the MVG vane. For other vanes, the flow remains attached due to a more efficient form. The aerodynamic shape of the vane also plays a role in the vortex formation. The accelerated flow on the forward part of the e 387 and NACA0012 vanes' suction side prevents the flow from rolling up, and the flow only rolls up and the vortex forms when the flow decelerates on the aft part of the vane. In contrast, the rectangle vane has a separation bubble on the forward section of the vane which allows for the flow to roll up and to form a vortex immediately.

The pressure distribution on the vanes at $\mathrm{y}=0.25 \mathrm{~h}, 0.5 \mathrm{~h}, 0.75 \mathrm{~h}$, and $0.9 \mathrm{~h}$ are shown in Fig. 11 . The pressure differential, much as on an aircraft wing, is the driving force of vortex formation on a VG vane. A positive pressure system forms on one side and a negative pressure system forms on the other. On the rectangle vane, the pressure differential is disrupted at half the length of the vane, approximately where the separation bubble is suppressed. The reduction in the pressure differential on the vane consequently causes the vortex formation to stop. The other vanes do not suffer such a collapse in the pressure distribution. The triangle and the e423 vanes maintain the pressure differential along the length of the vane allowing for the vortex formation to 
continue to the trailing edge of the vane. The continuous pressure differential similarly occurs on the NACA0012 airfoil, but the pressure differential is much weaker leading to a formation of a weaker vortex.

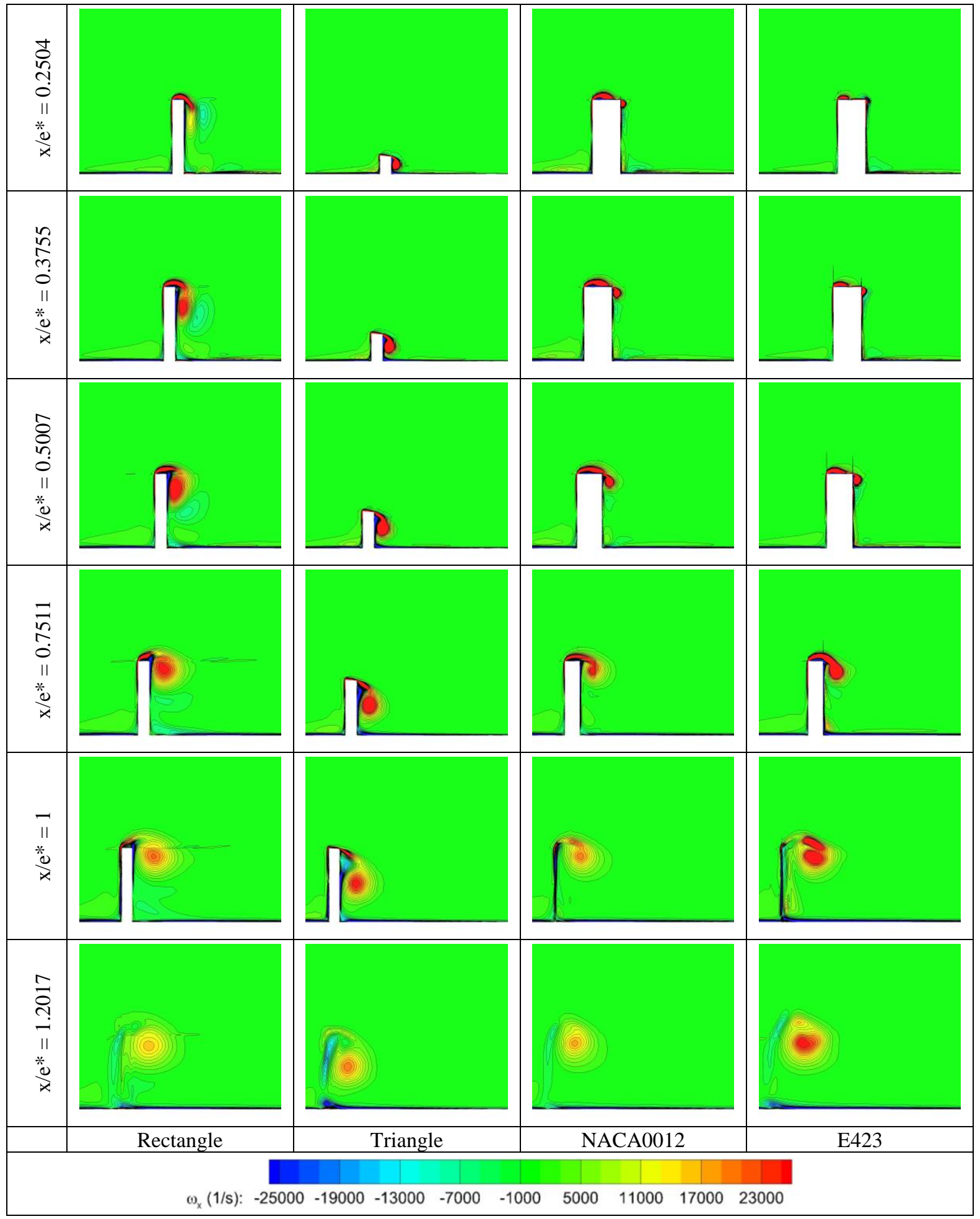

Figure 9: $\omega_{\mathrm{x}}$ at selected streamwise stations 


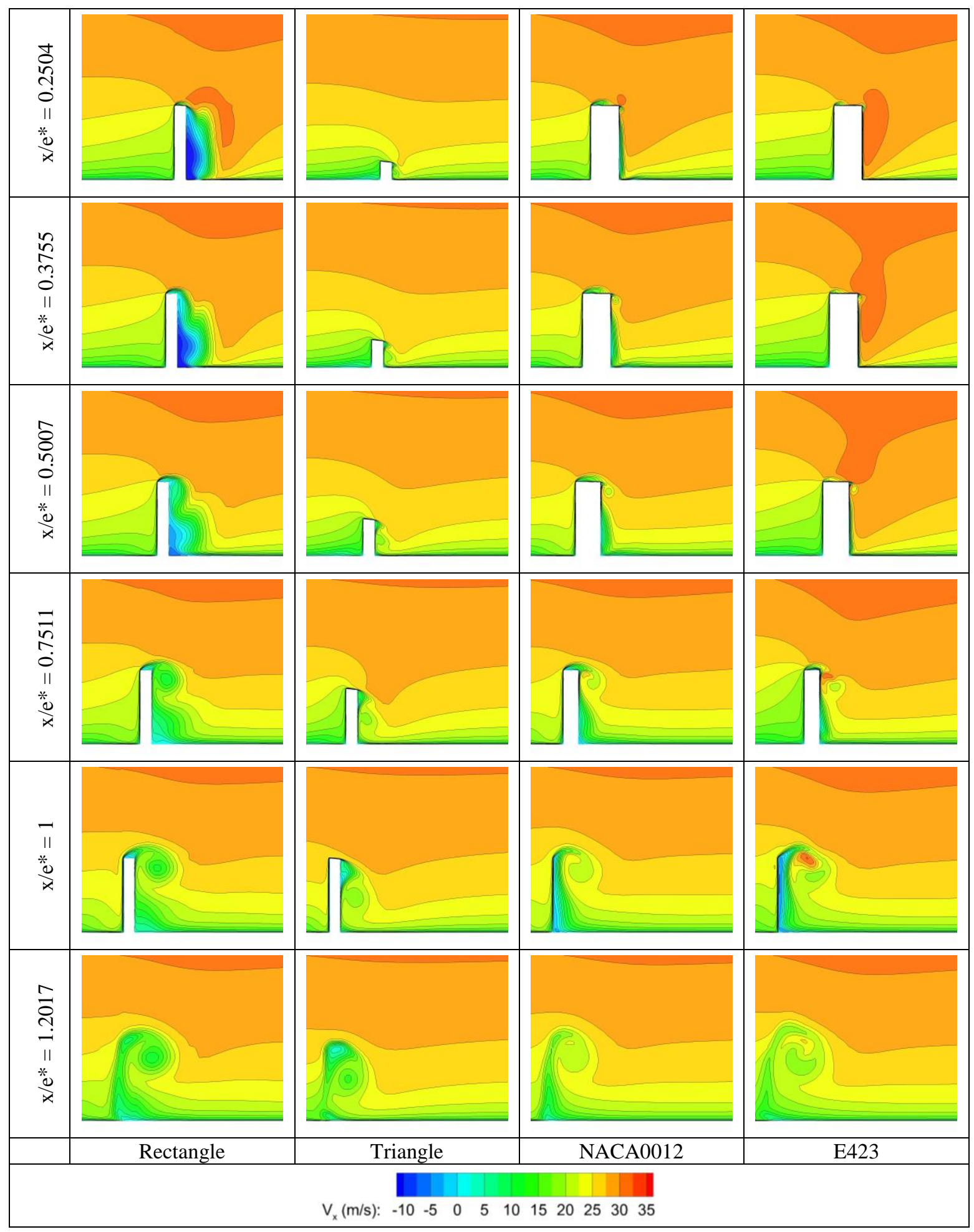

Figure 10: $V_{x}$ at selected streamwise stations 


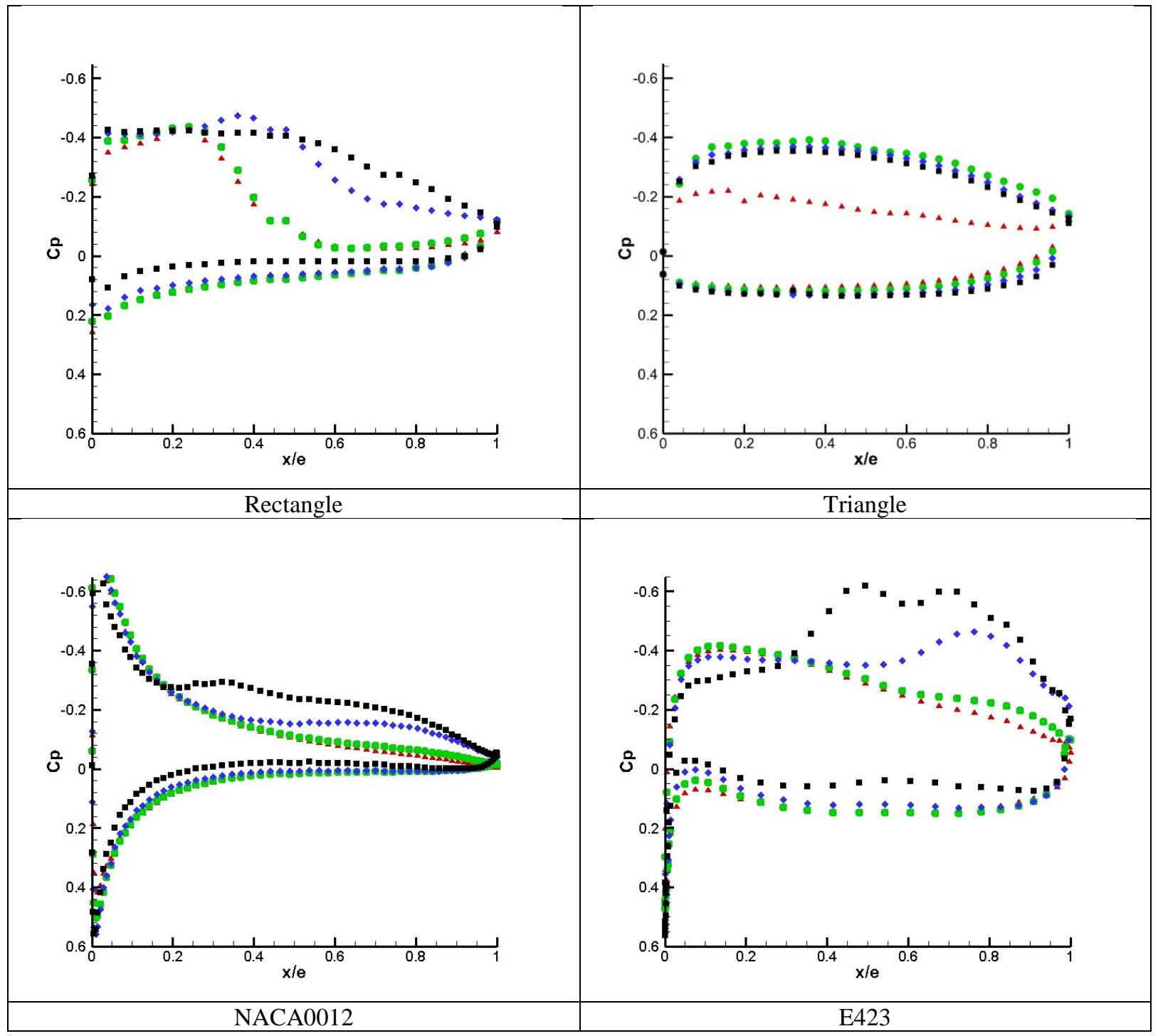

Figure 11: Pressure coefficient distribution on MVG vanes

$$
(\Delta-\mathbf{y}=0.25 h, \bullet-y=0.5 h, \diamond-y=0.75 h, \square-y=0.9 h)
$$

\section{Reynolds Number Effect}

In the prior subsection, the behaviour of MVGs at a selected Reynolds number was studied, i.e. $h^{+}=$ 607. It is of interest to observe the effect the Reynolds number has on the behaviour of a MVG. A rectangle MVG vane was modelled with the Reynolds number in the range of $90<h^{+}<1150$. The Reynolds number was altered by changing the freestream velocity while maintaining the boundary layer thickness at $35 \mathrm{~mm}$. The overall numerical setup was discussed in Section V. A derivative of Mesh A was used, but was altered to maintain a constant $y^{+}$at the wall and on the vane. The rectangle MVG vane was modelled at an angle of $18^{\circ}$ and $23^{\circ}$, and with a length of $3 \mathrm{~h}$.

With the alteration of the freestream velocity, Reynolds numbers of $90<h^{+}<1150$ were generated as shown in Fig. 12 and 13. This is at or below the Reynolds numbers tested by Ashill et al. [9], who tested 
Reynolds numbers of 750 to 2800 . For the tested range, circulation fitted a logarithmic relationship with the Reynolds number very well. Drag also fitted a logarithmic relationship with the Reynolds number. Ashill et al.'s [9] circulation data also expressed a logarithmic relation with the Reynolds number.

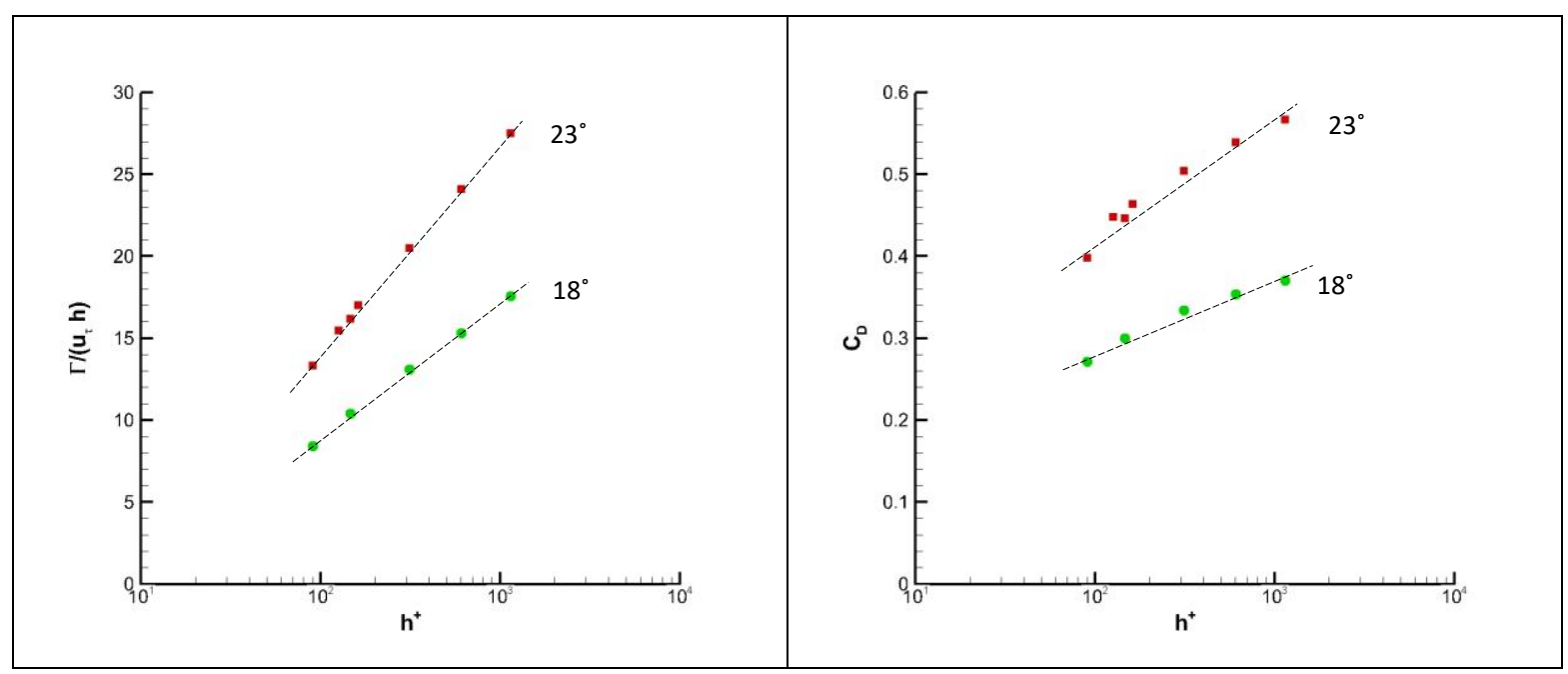

Figure 12: Initial circulation relationship with Reynolds number

Figure 13: Drag coefficient of MVG vane relationship to Reynolds Number

Taking the results from the MVG vane placed at $18^{\circ}$, the effect the Reynolds number has on the downstream behaviour of the vortex can be studied. The peak vorticity, circulation, and trajectory are plotted in Figs. 14, 15, 16, and 17, respectively. The peak vorticity in Fig. 14 increases with the Reynolds number at a similar trend found for the circulation. The relationship that the circulation has with the Reynolds number comes as no surprise considering the flow velocity increases. And given that the drag of the vane is mostly the result of the pressure drag that yields the vortex, drag will correspondingly increase with the Reynolds number too. The drag however does not increase as quickly as the circulation and the best circulation to drag ratio is observed at higher Reynolds numbers.

According to the vertical trajectory of the vortices in Fig. 16, the vortices propagate towards the wall until about $\mathrm{x} / \mathrm{h}=5$. Up until this point, the vortices follow a very similar path. After $\mathrm{x} / \mathrm{h}=5$, the vortices begin to interact with wall causing the vortex core to propagate away from the wall. Moreover, the paths of the vortices begin to diverge with the lower Reynolds number cases, projecting away from the wall faster than the vortices from the higher Reynolds number cases. From the angle that the vortices are formed, the vortices are imparted with momentum in the spanwise direction, as shown in Fig. 17. The spanwise movement of the vortices continue until they decay. The initial spanwise trajectory of the vortices are independent of the Reynolds number, however the paths of the vortices begin to diverge. The vortices of the low Reynolds number cases propagate less in the spanwise direction in comparison to the high Reynolds number cases. 


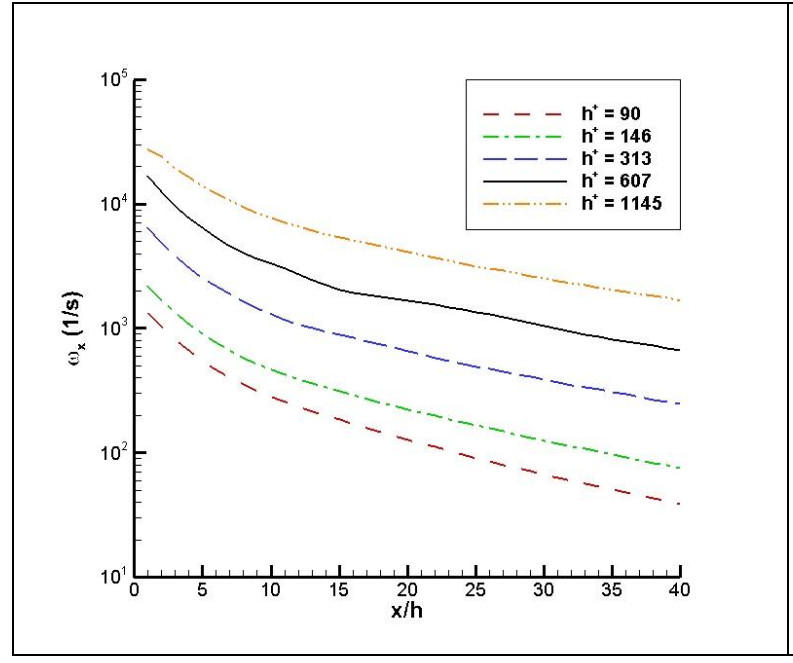

Figure 14: Dependency of the downstream vorticity on Reynolds number

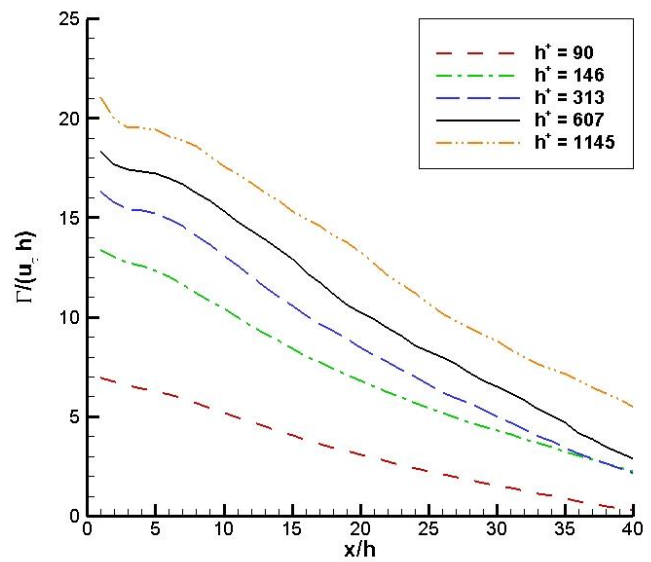

Figure 15: Dependency of the downstream circulation on Reynolds number

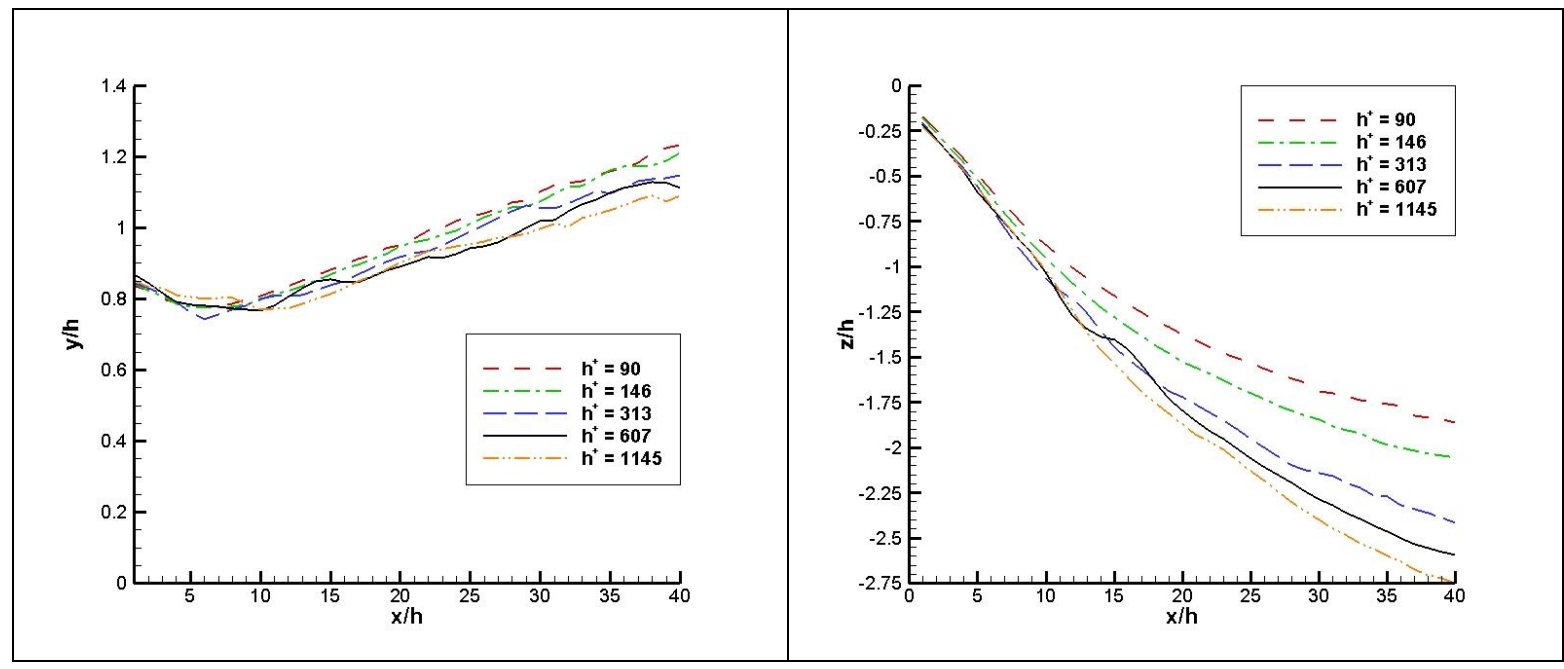

Figure 16: Dependency of the vortex's vertical trajectory on Reynolds number
Figure 17: Dependency of the vortex's horizontal trajectory on Reynolds number

\section{VII.Conclusion}

A numerical, parametric study was conducted into the efficiency of MVG vanes with a variety of shapes and angles. The efficiency of a MVG vane was determined by its circulation to drag ratio. Alongside the numerical results presented in this study, the drag of several MVG vanes were determined experimentally to validate the presented numerical results. A good match was found between rectangle $(\mathrm{e} / \mathrm{h}=7)$ and E423 vanes with less than a $4 \%$ difference between experimental and numerical results. A difference of $15 \%$ to $30 \%$ was observed between experimental and numerical results for the other tested vanes.

The parametric study found that triangle vanes had the best circulation to drag ratio, but triangle vanes also generate a small circulation compared to other vanes. The NACA0012 vanes have the second-best ratio 
followed by the E423 vanes. Rectangle vanes have a poor circulation to drag ratio compared to other vanes because of a separation bubble on the vanes' leading edge. The circulation generated by a MVG vane can be increased by increasing the angle vane, but increasing the angle beyond $18^{\circ} / 20^{\circ}$ was observed to decrease the circulation to drag ratio. The circulation to drag ratio of MVG vanes as a whole is limited by the induced drag of the vortex which follows an exponential function of circulation. This leads to conclusion that the weakest vortex producing vanes have the best efficiency without considering the required strength of the vortex downstream to suppress flow separation.

Further research was carried out to study how the circulation and drag of a rectangle vane varied over a wide-range of Reynolds numbers. It was shown that circulation had a strong logarithmic relationship with the device's Reynolds number while the drag had a slightly less defined logarithmic relation. Furthermore, increasing the Reynolds number showed an increase of the circulation to drag ratio. Future research will include the incorporation of the MVG design with group's CIRCLE method to redesign airfoil's geometry to achieve a high aerodynamic efficiency at high angles of attack [25].

\section{Acknowledgement}

The authors would like to acknowledge the technical support provided by DSTL and the EPSRC Turbulence Consortium under grant EP/L000261/1. The authors like to thank Mick Etheridge for the technical support provided to the experiments conducted in this paper.

\section{References}

[1] Ashill, P.R., Fulker, J.L., and Hackett, K.C., “A Review of Recent Developments in Flow Control,” The Aeronautical Journal, Vol. 109, No. 1095, 2005, pp. 205-232

[2] Lin, J.C., "Control of Turbulent Boundary-Layer Separation using Micro-Vortex Generators," 30th AIAA Fluid Dynamics Conference, AIAA, Norfolk, VA, 1999, pp. 1-16.

[3] Lin, J. C., Howard, F. G., and Selby, G. V., "Small Submerged Vortex Generators for Turbulent Flow Separation Control," Journal of Spacecraft and Rockets, Vol. 27, No. 5, 1990, pp. 503-507.

[4] Godard, G., and Stanislas, N., "Control of a decelerating boundary layer. Part 1: Optimization of passive vortex generators," Aerospace Science and Technology, Vol. 10, No. 3, 2006, pp. 181-191.

[5] Pauley, W. R., and Eaton, J. K. "Experimental study of the development of longitudinal vortex pairs embedded in a turbulent boundary layer," AIAA Journal, Vol. 26, No. 7, 1988, pp. 816-823.

[6] Chima, R. V., "Computational Modeling of Vortex Generators for Turbomachinery," ASME TURBO EXPO 2002, ASME, Amsterdam, 2002, pp. 1229-1238. 
[7] Canepa, E., Lengani, D., Satta, F., Spano, E., Ubaldi, M., and Zunino, P., "Boundary Layer Separation Control on a Flat Plate with Adverse Pressure Gradients using Vortex Generators," ASME TURBO EXPO 2006, Barcelona, 2006, pp. 1211-1220.

[8] Lin, J. C., Robinson, S. K., McGhee, R. J., and Valarezo, W. O., "Separation control on high-lift airfoils via microvortex generators," Journal of Aircraft, Vol. 31, No. 6, 1994, pp. 1317-1323.

[9] Ashill, P. R., Fulker, J. L., and Hackett, K. C., "Research at DERA on Sub Boundary Layer Vortex Generators (SBVGs)," 39th Aerospace Sciences Meeting and Exhibit, AIAA, Reno, NV, 2001.

[10] Ashill, P. R., Fulker, J. L., and Hackett, K. C., "Studies of Flows Induced by Sub Boundary Layer Vortex Generators (SBVGs)," 40th AIAA Aerospace Sciences Meeting \& Exhibit, AIAA, Reno, NV, 2002, pp. 1-13.

[11] Lin, J., Howard, F., Bushnell, D., and Selby, G., "Investigation of several passive and active methods for turbulent flow separation control," 21st Fluid Dynamics, Plasma Dynamics and Lasers Conference, AIAA, Settle, WA, 1990, pp. $1-20$.

[12] Allan, B. G., Yao, C.-S., and Lin, J. C., "Numerical Simulation of Vortex Generator Vanes and Jets on a Flat Plate," 1st Flow Control Conference, AIAA, St. Louis, MO, 2002, pp. 1-14.

[13] Wik, E., and Shaw, S. T., "Numerical Simulation of Micro Vortex Generators," $2^{\text {nd }}$ AIAA Flow Control Conference, AIAA, Portland, OR, 2004, pp. 1-13.

[14] Bender, E. E., Anderson, B. H., and Yagle, P. J. "Vortex Generator Modelling for Navier-Stokes Codes," ASME Paper No. FEDSM99-6929, 1999.

[15] Jirasek, A., "Vortex-Generator Model and Its Application to Flow Control," Journal of Aircraft, Vol. 42, No. 6, 2005, pp. 1486-1491.

[16] Florentie, L., van Zuijlen, A. H., Hulshoff, S. J., and Bijl, H. "Effectiveness of Side Force Models for Flow Simulations Downstream of Vortex Generators,” AIAA Journal, 2016, pp. 1-12.

[17] Jeong, J., and Hussain, F., "On the Identification of a Vortex," Journal of Fluid Mechanics, Vol. 285, 1995, pp. 6994.

[18] Haimes, R., and Kenwright, D. "On the velocity gradient tensor and fluid feature extraction," 14th Computational Fluid Dynamics Conference, AIAA, Norfolk, VA, 1999.

[19] Yao, C.-S., Lin, J. C., and Allan, B. G., "Flow-Field Measurement of Device-Induced Embedded Streamwise Vortex on a Flat Plate," 1st AIAA Flow Control Conference, AIAA, St. Louis, MO, 2002, pp. 1-16.

[20] Kendall, A., and Koochesfahani, M., "A Method for Estimating Wall Friction in Turbulent Boundary Layers," 25th AIAA Aerodynamic Measurement Technology and Ground Testing Conference, AIAA, San Francisco, CA, 2006, pp. $1-6$.

[21] Patel, V. C., "Calibration of the Preston Tube and Limitations on its use in Pressure Gradients," Journal of Fluid Mechanics, Vol. 23, No. 1, 1965, pp. 185-208. 
[22] Preston, J. H., "The Determination of Turbulent Skin Friction by Means of Pitot Tubes," Journal of Royal Aeronautical Society, Vol. 58, No. 518, 1954, pp. 109-121.

[23] "Quality Assessment for Wind Tunnel Testing," AGARD, Neuilly Sur Seine, France, 1994.

[24] Heffron, A., Williams, J. J., and Avital, E. J., "Flow Seperation and Passive Flow Control on E387 Airfoil," 54th AIAA Aerospace Sciences Meeting, AIAA, 2016, pp. 1-11.

[25] Shen, X., Avital, E., Paul, G., Rezaienia, M., and Wen, P., "Experimental Study of Surface Curvature Effects on Aerodynamic Performance of a Flow Reynolds Number Airfoil for use in Small Wind Turbines," Journal of Renewable and Sustainable Energy, Vol. 8, No. 5, 2016.

\section{Appendix}

\section{A. Experimental Drag Calculation}

For each survey, the stagnation and static pressure is known for a $104 \mathrm{~mm}$ by $22 \mathrm{~mm}$ grid, 53h behind the MVG. The grid contains 24 boundary layer profiles. At each surveyed point, the velocity was determined and non-dimensionalized by the freestream velocity. Making use of the equation for the momentum thickness of a boundary layer, the drag per unit distance in the spanwise direction $(\mathrm{z})$ can be determined by:

$$
\frac{\partial D_{m v g}}{\partial z}=\rho U_{o}^{2} \int \frac{u}{U_{o}}\left(1-\frac{u}{U_{o}}\right) d y
$$

The resulting value for each boundary layer profile is subtracted by the base case without a MVG vane. Each profile is then numerical integrated in the spanwise direction.

$$
C_{D}=\frac{2}{\rho U_{o}^{2} h^{2}} \int\left(\frac{\partial D_{m v g}}{\partial z}-\frac{\partial D_{\text {base }}}{\partial z}\right) d z
$$

\section{B. Calculation Experimental Friction Velocity}

The friction velocity at the location of the MVG was calculated via two methods, a curve fitting method suggested by Kendall et al. [19] and a correlation method developed by Patel [20]. The method developed by Kendall et al. [19] makes use of the Spalding profile to calculate the mean boundary layer profile:

$$
y^{+}=u^{+}+\exp (-\kappa B)\left[\exp \left(\kappa u^{+}\right)-\kappa u^{+}-\frac{1}{2}\left(\kappa u^{+}\right)^{2}-\frac{1}{6}\left(\kappa u^{+}\right)^{3}-1\right]
$$

where

$$
\begin{gathered}
y^{+}=\frac{y u_{\tau}}{v} \\
u^{+}=\frac{U}{u_{\tau}}
\end{gathered}
$$


and $\kappa=0.5$ and $B=0.5$. With Eq. B1, a MATLAB routine was written to find the $u^{+}$that matched the Spalding profile with the experimental data. The written programme found the correct $u^{+}$by finding the minimum residual.

$$
\mathrm{R}=\frac{1}{N} \sum_{i=0}^{N} \frac{\mid u_{i}^{+}(\text {data })-u_{i}^{+}(\text {model }) \mid}{u_{i}^{+}(\text {model })}
$$

Patel's correlation method [20] is an extension of Preston's method [21]. Preston's method uses a simple pitot tube, called a Preston tube, that rests on the wall of the wind tunnel. Assuming that the Preston tube is placed in a region that scales with the inner boundary layer variables, a similarity function can be constructed between dynamic pressure and wall shear stress.

$$
\frac{\tau_{w} d^{2}}{4 \rho u^{2}}=f\left(\frac{\Delta p d^{2}}{4 \rho u^{2}}\right)
$$

Through experiments, Preston [21] empirically determined and calibrated a function to match experimental measurements. Patel [20] expanded and improved the empirical function, the new function is valid from $1.5<$ $y^{*}<3.5$ and $11.2<R e_{d}<110 . R e_{d}$ is the Reynolds number based on the outer diameter of the Pitot tube (d) and the friction velocity. The empirical relation that Patel determined was:

$$
y^{*}=0.8287-0.1381 x^{*}+0.1437 x^{* 2}-0.0060 x^{* 3}
$$

The variables $x^{*}$ and $y^{*}$ are definged as:

$$
x^{*}=\log _{10}\left(\frac{\tau_{w} d^{2}}{4 \rho v^{2}}\right) \quad \text { and } \quad y^{*}=\log _{10}\left(\frac{\Delta p d^{2}}{4 \rho v^{2}}\right)
$$

